\title{
MODES AND MOVES OF PROTEST
}

\section{Crowds and Mobs in Nathan Hill's The Nix}

Tre he role of mass protest constitutes one of the most central and at the same time controversial elements that have characterized American culture ever since the very foundation of the United States, and even prior to its formation. Central, because American history presents significant waves of collective protest movements, palimpsetically symptomatic of various forms of popular discontent as opposed to the relative structure of state power; chronologically speaking, one of the first cases of contrast between the collective popular dimension and authorities dates back to the March 5th, 1770, Boston Massacre, when-exasperated by the Townshend Acts passed by the English Parliament-a group of colonial subjects protested and provoked a squad of British soldiers whom, intimidated by the crowd's aggressive potential, opened fire on the unarmed civilians, killing five people and wounding six more. Several other cases redolent of such dialectics have permeated US history up until the contemporary period, for example, the Shays's Rebellion (1787), the New York Draft Riots (1863), the Houston Riot (1917), the whole anti-Vietnam War pacifistic movement during the 1960 s and 1970s, and, most recently, the Occupy Movement, which erupted in New York on November 17th, 2011.

At the same time, the collective manifestation of dissent has recurrently proved to be controversial, since despite-or because of-its historical persistence, American mass protest has constantly generated a bias about the radical potential of mobs
Nicola Paladin University

"G. D’Annunzio" at Chieti-Pescara Italy

(D) 
and crowds, thus constructing an opposition-both practical and rhetorical-between popular subversive tensions, and a more elitist "conservative" and self-preserving struggle, whose aim has been that of containing the popular tensions in order to prevent them from disrupting the social order.' Ronald P. Formisano contends that "after 1789 the Revolution continued to serve as a template for popular action" (Formisano 2008: 44), and Jeremy Engels seems to agree as he identifies the origins of the "American demophobia" during the American Revolution, describing it as a fear of the revolutionary elites for the potential radicalism² of the people and their claims of sovereignty which ignited a "long history of wars meant to secure the borders of the demos and eliminate the foreign influences that might prey on democratic weakness"3 (Engels 2010: 19).

The centrality of mass protest in American culture is reflected in terms of literary representation and constitutes a recurrent element of interest in the most demophobic XIX century American classics, such as Edgar Allan Poe's “The Man of the Crowd” (1840), and Nathaniel Hawthorne's "My Kinsman Major, Molineaux" (1831), including also some well-known occurrences in the XX century, such as John Steinbeck's In Dubious Battle, published in 1936, or Nathaniel West's 1939 novel, The Day of the Locust. Grounding on the work by J. S. McClelland, ${ }^{4}$ in her The Aesthetics and Politics of the Crowd in American Literature, Mary Esteve recognizes the same biased perception of crowds and mobs in the way they are narrated, namely

1968 Transnational Legacies

1. Michael Hardt and Antonio Negri associate the ensemble of nation-state structure to the notion of empire to which the multitudes are naturally juxtaposed. Hardt and Negri claim that the multitudes' struggles "have produced Empire as an inversion of its own image and who now represent on this new scene an uncontainable force and an excess of value with respect to every form of right and law" (Hardt and Negri 2000: 394).

2. I make reference to Gordon S. Wood's groundbreaking The Radicalism of the American Revolution (1992). According to Wood, "If we measure the radicalism by the amount of social change that actually took place-by transformations in the relationships that bound the people to each other-then the American Revolution was not conservative at all" (Wood 1992: 14).

3. As Larry Reynolds affirms, "the demonization of one's enemies often constituted the cultural justification for inflicting violence on them" (Reynolds 2008: 23).

4. See McClelland, J.S. The Crowd and the Mob. From Plato to Canetti. Unwin Hyman, 1989. 
from an antagonistic point of view opposed to the "prevailing political practices:" not surprisingly, "these crowds had a crucial discursive role to play, one that, for reasons elaborated below, can be termed aesthetic. Such figures of the crowd did ultimately bear political meaning, but it was a negative meaning; it entailed the negation of their place at the political-liberal table" (Esteve 2003: 3).

Building on Esteve's reflection, the starting point of the present research resides in the problematic circularity which characterizes crowds and mobs in American culture. As a matter of fact, protesting crowds embody dissent in the American people, but, at the same time, the tangible consequences of their actions impact the social order in which the American people live. In other words, the manifestation of dissent may be read both as a claim for democratic rights and as a degeneration of those same rights which results in anarchic mobocracies. The same process can be detected in the opposite perspective, namely when crowds are repressed by the state military power-the example, par excellence, of a repressive state apparatus-within a sort of "state of exception," following a classic Althusserian formulation: "The state is a machine of repression, which enables the ruling classes [...] to ensure their domination over the working class" (2008: 11). Containment and repression of the citizen's right to protest are considered as justifiable measures inasmuch as they can protect the rest of the citizens' rights. This form of circularity-both from the standpoint of mobs and from that of the authorities-is the prerogative of an endocrine system of relationships. Such a condition changed dramatically in 2001, when post 9/11 rhetoric on the "War on Terror" and the spread of terrorist suicidal attacks all over the world contributed to "open" the American self-perception of society, transforming the system from endocrine to exocrine. This shift of paradigm has originated two new ongoing narratives: first, the irruption of an external dangerous entity, and second, the subsequent transformation of any American crowd from a potential threat to social order, to a potential victim of an external danger. ${ }^{5}$

5. Although the turning point which determined a reconfiguration of American crowds as potential targets is unanimously identified with the 9/11 attack on the Twin Towers, this vision has been significantly consolidated by other 
In the light of these premises, the purpose of this essay is to demonstrate the emergence of this new and historically peculiar connotation of crowds and mobs in America, and in particular, how the notion of victimhood should be considered not as a substitute to that of the persecutor, but rather as a complement. Mass protests do not cease to be perceived as a possible threat to social order, as Custave Le Bon argues by stating that "Crowds are only powerful for destruction" (2002, xiii), but they acquire a new trait of consideration from the state power, that of a potential target to aim at (and thus, a potential victim to protect): the two connotations co-exist dialectically. Such a binary nature of American crowds in the light not only of their disruptive power but also of their victimhood, stands out in Nathan Hill's recent novel The Nix published in 2016. The first section of this essay will be dedicated to underlining this duality. In the second part, descriptions of mobs from The Nix will be compared with some of the most canonical "demophobic" texts of the Classic American literary tradition-Poe's "The Man of the Crowd," Hawthorne's "My Kinsman, Major Molineaux"-in order to understand where Hill's crowds' dual identity detaches itself from their traditional literary paradigm.

The Nix narrates the story of Samuel Anderson, an English associate professor who works in a small city college in Chicago, and whose monotonous life is mainly characterized by, first, a deep passion for World of Elfscape, an online role-playing video game to which he devotes the majority of his spare time, second,

1968 Transnational Legacies a discouraged love for his childhood sweetheart, Bethany, his best friend's twin sister, and finally, a never-resolved relationship with his mother, who abandoned him, along with his father, when he was still a child. The book starts in 2011 when Faye, Samuel's runaway mother, suddenly becomes famous for being charged after throwing pebbles at the Republican Trumpish presidential candidate, Sheldon Packer. Thanks to her instantaneous celebrity, Samuel meets his mother and tries to reconstruct her life ever since she had left him in 1988, all the way back to 1968, and in particular,

attacks which took place in the following years, both in the United Statessuch as the Boston Marathon Bombing, on April 15th, 2013-and in Europe, for example, the attack to the Bataclan theatre which occurred on November 13th, 2015 in Paris. 
to the Chicago Democratic Convention protests, in whose events he discovers she had participated. The novel is structured on three different chronological levels, corresponding to the three years above-mentioned, and posits a strong relation of concordance between 1968 counter-culture mass protest, and the 20110 ccupy Wall Street eruption, which is observed as the nearer against the grain of the latter.

The second part of the 1968 section of The Nix is set at the core of the Chicago rallies mobilized on occasion of the Democratic National Convention, and pictures what was defined as the "pitched battle," namely a peak of violence and chaos between the agents of the Chicago Police Department that took place in front of the Conrad Hilton Hotel, where the convention was being held. Hill's depiction of the "pitched battle" seems to perfectly illustrate the double and dialectical nature of crowds and mobs, first as victims of repression, then as a practically destructive force. Throughout the entire scene, the voice and the point of view correspond to those of the CBS reporters who film and comment "live" upon the moves of the Chicago crowd and of the Chicago PD. Even before any form of mutual aggression between the two parts, the element that emerges more vehemently concerns the atmosphere, which the reporters describe as entirely permeated by a "pure combative sensation" (Hill 2016: 494). The reader perceives such a feeling through the warlike descriptive mode that characterizes the section: the reporters and live images in the news are reported from cameras secured to helicopters that fly over the area. The aircrafts are recurrently defined as "choppers," thus adapting the military lexicon in use in Vietnam, to the civilian context of the time, thus suggesting an implicit level of militarization of the "home front."

Yet, the "combative sensation" transpares very evidently in the representation of the mob of protesters and the police forces, which are accurately described in the military way they deploy and move, thus suggesting their latent violent and aggressive potential. The first section to reify this tension is almost entirely composed of women: "girls walking south in the middle of the street. This is action. This is news untouched. Especially now as a cop car rolls up and instead of dispersing like they ought to the girls actually attack the cop car! Jabbing at the siren with baseball bats! 
Breaking the windows with rocks! [...] Then the girls all gather on the car and it looks like a bunch of ants surrounding a beetle ready to devour it" (Hill 2016: 487). The action of the women is univocal and regiment-like: they move together and occupy the public space in a militaristic way, at first moving together, then attacking collectively as one sole being. As the section proceeds, the potentially destructive force of the mob becomes explicit and degenerates to the point that their violence is dehumanized and described through a brutal natural metaphor.

Later on, the aerial perspective of the reporters anticipates to the reader a panoramic vista of what the crowd of rioters will face: "About a hundred cops in riot gear wait for the girls, and behind them a platoon of National Guardsmen in gas masks, holding rifles with fucking daggers attached to the barrels, and behind them this monstrous metal thing with nozzles on the front like some kind of terrible Zamboni from the future that the TV folks tell them the purpose of, which is gas. Tear gas. A thousand gallons" (Hill 2016: 493). When the mob of women and the regiment of riot policemen reciprocally enter into each other's visual field, the aggressive crowd switches roles and converts into the victim of the police's repression, and tries to disperse: "But the police are on the move now. Nightsticks out, riot helmets down, and running, sprinting, and when the girls understand what is about to happen their big march breaks apart, like a rock exploded by gunshot, pieces of it flying off in every direction. Some girls head back

1968 Transnational Legacies from the direction they came, only to be cut off by a paddy wagon and a squadron of cops who anticipated this very move" (Hill 2016: 494). The militaristic connotation of this scene, as it is epitomized by the metaphor of a stone, the protester's weapon par excellance, the symbol of the Palestinian Intifada, exploded into fragments by a bullet, is symbolically representative of the police repression.

The increasing tension that permeates the scene is exasperated and set to explode as the police fires tear gas, thus causing an unregulated move by the mob: 6

6. In Stephen King's short story "Hearts in Atlantis," which gives the title to the entire collection, the protagonist Peter Riley suggests some survival tips he reports to have learned during the 1968 Chicago protests, and he focuses 
The gas was fired-purposefully or accidentally, it's not known-so that it landed behind most of the crowd, which means the only way to avoid the misery of the gas is to run the other way, in the direction of Michigan Avenue and the Conrad Hilton and the vast police blockades, and so the volume problem is that there are way more people wanting to be on Michigan Avenue than there is currently space on Michigan Avenue for these people. It's your unstoppable force meeting its immovable object, the body mass of ten thousand protestors running headlong into the teeth of the Chicago PD. (Hill 2016: 520)

The conclusion of these few lines unveils the evolution of the events. The police forces are alluded to as a ferocious animal, and, by consequences, the rioters are reshaped as a victim which runs straight "into the teeth of the Chicago PD," whose repressive mode, in turn, reaches its peak of efficiency and violence: "The protestors yell 'Peace!' or 'I'm not resisting!' and they hold up their hands, palms out, surrendering, but the cop clobbers them anyway, in the head, the neck, the belly" (Hill 2016: 530), and the reporters themselves explicitly denounce what the mob-victim is subjected to, namely a state-of-exceptional suspension of the civil rights imposed by the police. The reporters establish a comparison between the events in Chicago and the Soviet occupation of Prague, which occurred only a few days before the Democratic Convention, on August 20th and 21st, not only underlining the military connotation of the intervention but also signaling the momentary exceptional interruption of democracy. "In Chicago, in 1968, I learned that cops can beat the shit out of you no matter how well you cover up" (King 1999: 244), sharply recollects Peter Riley in Stephen King's Heart in Atlantis, and Hill depicts a fairly similar situation:

Police are beating people with impunity, the journalists say on CBS News. They demand transparency. Accountability. They say the police have removed their badges and hidden their faces because they know what they're doing is illegal. Comparisons are made to the Soviets rolling into Prague earlier this year, running down and overwhelming the poor Czechs. The Chicago PD is acting like that, the journalists say. It's Czecho-

on tear gas and nightsticks: "I learned that you should try to get downwind of teargas and breathe slowly through a handkerchief or a bandanna if you couldn't do that. I learned that when the nightsticks come out, you want to fall on your side, draw your knees up to your chest, and cover the back of your head with your hands" (King 1999: 244). 
slovakia west. Czechago is a word it does not take long for someone clever to make up (Hill 2016: 515).

The last part of the "pitched battle" section shows another and more extreme case in which the mob's role switches again from that of the victim to that of the perpetrator, thus actualizing its latent destructive potential. In the middle of the "battle," Officer Brown, a disturbing secondary character who had been persecuting Faye during the days before the manifestation for sentimental issues, spots the girls in the riot and aims at her in order to beat her and revenge his frustrated obsession for her. Brown intentionally crosses the police cordon and addresses a group of protesters all gathered against the glass walls of the Conrad Hilton Hotel. Within a few instants, when Brown is about to strike Faye's head with his nightstick, more tear gas is shot from the rear. Already familiar with the effects of the gas, the crowd automatically reacts and moves unpredictably, in part counter-charging the police, in part trying to escape. The force of the crowd's motion causes the glass walls of the Hilton to crash: "The window doesn't even really crack so much as explode sharply everywhere all at once. And Faye and the cop and the great rush of protestors pushing themselves against it all collapse and tumble backward into the people and smoke and music of the Haymarket Bar" (Hill 2016: 530). The episode hyperbolically demonstrates the unpredictability of a mob's action and the circularity of its status: on the one hand, one of the consequences of the collective action is to let

1968 Transnational Legacies Faye free to escape from Brown, in a way protecting her from the police repressive violence; yet, on the other hand, the mob is also responsible for a tragic accident: once the tear gas is shot, Brown is pushed backward from the mob against the crashed glass shards which damage his spine and provoke his irreversible partial paralysis.

Some of the most prominent dynamics that Nathan Hill outlines in his representation of the relationship between the people and the authorities, share several of the same traits that the classic American literary tradition presents in dealing with mobs and crowds. The depiction and conceptualization of crowds imply a central preoccupation in the American mind, that of preserving unaltered the rights and principles that regulate the mythical "people" 
of the United States. Such a notion was invented in the revolutionary years and crystallized in The Declaration of Independence as well as in the US Constitution. Although several authors praised the importance of masses in American democracy, such as Lydia Maria Child in her Letters from New York (1841), or Walt Whitman in Democratic Vistas (1871), ${ }^{8}$ the "passionate impulses" of the collectivity constituted a constant element of anxiety for other classic American authors, Edgar Allan Poe and Nathaniel Hawthorne in particular.

As Esteve contends, though for different socio-political readings of their contemporary epoch, both of them develop "demophobic vistas." Again, according to Esteve, their negative perception of crowds is associable to a change of cultural paradigm: "the aesthetic relation to the crowd is more akin to the sublime than the beautiful in that the crowd takes on qualities of a startlingly powerful nature, through its inanimacy, impersonality, and size" (Esteve 2003: 16). Later on in her book, Esteve integrates her aesthetic interpretation of crowds with a more political and contingent reading, and she resorts to Chantal Mouffe's notion of "extreme pluralism," namely a "multiplicity of identities without any common denominator, and it is impossible to distinguish between differences that exist but should not exist and differences that do not exist but should exist" (Mouffe 1996: 30).

7. Michael Hardt and Antonio Negri argue that "The concept of the People no longer functions as the organized subject of the system of command, and consequently the identity of the People is replaced by the mobility, flexibility, and perpetual differentiation of the multitude. This shift demystifies and destroys the circular modern idea of the legitimacy of power by which power constructs from the multitude a single subject that could then in turn legitimate that same power" (Hardt and Negri 2000: 344).

8. Whitman's fascination for collectivity stands out as one of his primary elements of interest in "Song of Myself:" his positive reading of collective action should not surprise in the light of the several references that the poet proposes about the multitudes that he can contain (not limited to stanza 51). 9. This expression was used by Nathaniel Hawthorne in his essay, "Chiefly About War Matters," published in 1862, and it implied a condemnation of those impulses inasmuch as they posed a danger for civil society. Larry J. Reynolds affirms that "For Hawthorne, strong feelings not under the control of the intellect posed a grave threat not only to individuals but also to societies and nations" (Reynolds 2008: 15). 
The integration of a sublime descriptive mode and a political understanding of mobs' chaotic agency is particularly evident in two aspects that emerge from Edgar Allan Poe's "The Man of the Crowd" and Nathaniel Hawthorne's "My Kinsman, Major Molineaux." The most strikingly descriptive strategy that both short stories share is the large use of water-related imagery, a choice which is able, at the same time, to convey a sublime reverential fear for the power of nature, and, in sociological terms, to successfully describe the collective action of a mob. In "The Man of the Crowd," the narrator describes the streams of people moving in London and, at a certain point, he reports that "the throng momently increased; and, by the time the lamps were well lighted, two dense and continuous tides of population were rushing past the door" (Poe 1841). Every time the narrator refers to the crowd of Londoners, he is fascinated by the absolute impossibility to apply distinctive categories to the mass of people: "There was nothing very distinctive," he claims, thus alluding once again to the homogeneous uniformity of water, whose components are-almost pointless to underline-indistinguishable.

The same imagery is hinted at in "My Kinsman, Major Molineaux." During the second half of the tale, Robin Molineaux comes across a mob of villagers who have tarred and feathered his kinsman, Major Molineaux. The young protagonist is dragged into the group of people and later on, he "started, and withdrew his arm from the stone post to which he had instinctively clung, as the living

1968 Transnational Legacies stream rolled by him." As in the case of "The Man of the Crowd," Hawthorne connotes the raging mobs by underlining its uniformity as well as its destructive potential, a vision which permeates his literary production: as a matter of fact, according to Larry Reynolds, "Hawthorne possessed a constitutional aversion to abrupt change, in whatever form it came-personal, social, political. Although he appreciated the vitality evident in mass transformative action, it also evoked his anxiety and resistance, especially when it involved crowds and mobs" (Reynolds 2008: 14).

What emerges quite strikingly in The Nix, following a pattern structured upon water-related metaphors and similes, is a certain solution of continuity that connects Hill's way of dealing with multitudes and the classics. In the main scene of the Chicago protest, 
the rally is described as a "moving human river [that] pressed at all sides and sometimes even lifted off her feet for a moment and carried, a sensation like swimming or floating, before being dropped again" (Hill 2016: 527). Later on, the narrative perspective of the CBS reporters continues and states that "the crowd is too thick, the current too strong," and when the report portrays the pitched battle in front of the Conrad Hilton, the depiction says that "The first of them flow onto Michigan Avenue and into the walls of the Conrad Hilton like runaway waves. They splash onto the concrete and brick and they're pinned there as the police recognize that something has shifted in the rhetoric of the day" (Hill 2016: 527).

In a sense, one might argue that Nathan Hill's implication of a watery semantic area is broader and more articulated than in classic demophobic texts, and at the same time, Hill's use is probably more aware; during the riot, a journalist declares: "Imagine a single drop of water: that's the protest. Now put that drop of water into a bucket: that's the protest movement. Now drop that bucket into Lake Michigan: that's Reality" (Hill 2016: 512).

In conclusion, in his depictions of contemporary mobs and crowds, Nathan Hill does not entirely subvert the American demophobic literary tradition. In fact, his reconstruction of the 1968 Chicago protests shares a considerable amount of elements-both thematic and linguistic-which had pertained to several canonical authors of the first half of the XIX century (not limited to Poe and Hawthorne, but extensible to Washington Irving and, partially, to Herman Melville). Yet, what Hill seems to suggest in relation to the evolution of American history and the weakening of the US exceptional state narrative which had lost its virginal aura of righteousness, ${ }^{10}$ is a shift in the ethics of mass protest. In particular, where tradition had always connoted collective actions as forms of resistance to the legitimacy of the US government, Hill proposes a provocative twist in which, although the antagonism remains the same, it is the legitimacy of the state's prerogative that is contested. In other words, Hill does not contradict the potentially disruptive power of mobs, but at the same time, he does not proclaim the infallibility

10. See Pease, Donald E. The New American Exceptionalism. University of Minnesota Press, 2009. 
of the state's repressive mode, which he compares to the Soviet regime. In addition to that, the examination of the 1968 protests against the grain of the Occupy Movement implies an automatic reconsideration of the legitimacy of the protesters' standpoint: the Occupy activists defined themselves as "the 99\%," claiming de facto to represent the unanimity of the population, thus theoretically interrupting the paradox of a popular movement whose protest might negatively affect the conditions of the rest of the people.

As a consequence, Hill's historical contingency undoubtedly influenced his reconfiguration of mass protest, confirming their dual nature as both a subversive force and a victim. Such a divergent conceptualization of mobs and crowds constitutes the most significant aspect of transformation that exists between classic American demophobic texts and The Nix. Paradoxically though, despite his representation of the circular nature of mobs, Nathan Hill succeeds where authors such as Irving, Poe, or Hawthorne "failed," that is in depicting the actual threat posed by an uncontrolled mob. In The Nix, the constant disruptive potential of mobs becomes explicit and dangerous (rather than potentially dangerous), whereas the most famous mob scenes in American literary tradition present mobs and crowds as bearers of latent dangers which never become actually explicit. At the same time, in the light of the historical contingency to which Hill belongs and which he represents, a redefinition in the role of mass protest has become

1968 Transnational Legacies necessary. The neo-populist wave, " at the core of which The Nix situates itself, requires a deeper process of scrutiny in the analysis of mass protest: every form of protest is indeed the result of the combination between form and content. If, on the one hand, form has historically proved to be a palimpsest structured on recurrent dynamics, as Formisano demonstrates, on the other hand, the content of a protest necessarily plays a fundamental part in the legitimization of a collective manifestation of dissent and posits the new deterritorialized categories according to which

11. I refer particularly to Jan-Werner Müller, What is Populism? : Unversity of Pennsylvania Press, 2016, Mark Rolfe, The Reinvention of Populist Rhetoric in the Digital Age. Palgrave \& MacMillan, 2016, and James Ball. Post-Truth. How Bullshit Conquered the World. Biteback Publishing, 2017. 
dissent should be addressed and understood beyond the modern dualistic limited vision of multitudes constituting either crowds, or mobs.

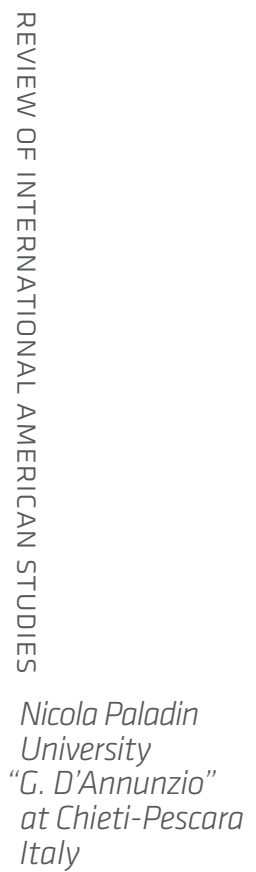


WORKS CITED

Agamben, Giorgio. State of Exception. The University of Chicago Press, 2005.

Althusser, Louis. On Ideology. Verso, 2008 (1971).

Ball, James. Post-Truth. How Bullshit Conquered the World. Biteback Publishing, 2017.

Borch, Christian. "Body to Body: On the Political Anatomy of Crowds." Sociological Theory, 27: 3 (Sept. 2009), 271-290.

Bouton, Terry. Taming Democracy. "The People," the Founders, and the Troubled Ending of the American Revolution. Oxford UP, 2007.

Brill, Lesley. "Terrorism, Crowds and Power, and the Dogs of War." Anthropological Quarterly, 76: 1 (Winter 2003), 87-94.

Canetti, Elias. Crowds and Power. Continuum, 1962.

Engels, Jeremy. Enemyship. Democracy and Counter-Revolution in the Early Republic. Michigan State University, 2010.

Esteve, Mary. The Aesthetics and Politics of the Crowd in American Literature. Cambridge UP, 2003.

Formisano, Ronald P. For the People. American Populist movements from the Revolution to the 1850s. The University of North Carolina Press, 2008.

Hardt, Michael, and Negri, Antonio. Empire. Harvard UP, 2000.

1968

Transnational Legacies

Hawthorne, Nathaniel. "My Kinsman, Major Molineaux." The SnowImage and Other Twice-Told Tales. Ticknor, Reed, and Fields, 1853. <http://www.hawthorneinsalem.org/mirror_eldritch/ mm.html>. Accessed on October 28th, 2018.

Hill, Nathan. The Nix. Alfred A. Knopf, 2016.

King, Stephen. Hearts in Atlantis. Scribner, 1999.

Le Bon, Gustave. The Crowd. A Study of the Popular Mind. Dover Publications, 2002 (1895).

McClelland, J.S. The Crowd and the Mob. From Plato to Canetti. Unwin Hyman, 1989.

Mouffe, Chantal. "Democracy, Power, and the Political." Democracy and Difference, edited by Seyla Benhabib. Princeton UP, 1996. 
Müller, Jan-Werner, What is Populism? Unversity of Pennsylvania Press, 2016.

Nelson, Dana D. Commons Democracy. Reading the Politics of Participation in the Early United States. Fordham UP, 2016.

Pease, Donald E. The New American Exceptionalism. University of Minnesota Press, 2009.

Poe, Edgar Allan. "The Man of the Crowd." <http://xroads.virginia. edu/ hyper/poe/manofcro.html>. Accessed on November 1st, 2018.

Reynolds, LarryJ. Devils and Rebels. The Making of Hawthorne's Damned Politics. The University of Michigan Press, 2008.

Rolfe, Mark. The Reinvention of Populist Rhetoric in the Digital Age. Palgrave \& MacMillan, 2016.

Smith, Barbara C. "Food Rioters and the American Revolution." The William and Mary Quarterly, 51: 1 (Jan. 1994), 2: 38.

Westley, W. A. "The Nature and Control of Hostile Crowds." The Canadian Journal of Economics and Political Science, 23: 1 (Feb. 1957), 33-41.

Wood, Gordon S. The Radicalism of the American Revolution. Alfred A. Knopf, 1992. 
